\title{
SHEAR BOND STRENGTH FOR IMMEDIATE AND DELAYED REPAIR OF COMPOSITE WITH MICROHYBRID AND NANOHYBRID RESINS USING DIFFERENT BONDING AGENTS
}

\author{
Eman A. Kholief ${ }^{1 * B D S}$, El Sayed M. Mahmoud ${ }^{2} P h D$, Sonia M. El Chabrawy ${ }^{3}$ hD.
}

\section{ABSTRACT:}

INTRODUCTION: Repair is indicated mainly in the event of localized shortcomings that are clinically unsatisfactory and no longer acceptable; it implies in any case the addition of a restorative material.

OBJECTIVES: Shear bond strength for immediate and delayed repair of composite with microhybrid and nanohybrid resins using different bonding agents.

MATERIALS AND METHODS: One hundred sixty nanohybrid composite discs were prepared. They were divided into 16 groups (10 each) according to 3 factors: Factor 1: Repair time, Factor 2: Repair protocol and Factor 3: Repair composite material. For immediate repair (I), discs $(n=80)$ were divided into 4 subgroups 20 discs each. Each subgroup was divided into 2 groups as follows Group 1 (a): no conditioning with nanohybrid composite, Group 1 (b): no conditioning with microhybrid composite, Group 2 (a) Adhese Universal bond with nanohybrid composite, Group 2 (b) Adhese Universal bond with microhybrid composite, Group 3 (a) All-Bond Universal with Nano-hybrid composite ,Group 3 (b) AllBond Universal with microhybrid composite, Group 4 (a) Scotchbond ${ }^{\mathrm{TM}}$ Universal with nanohybrid composite, and Group 4 (b) Scotchbond ${ }^{\mathrm{TM}}$ Universal with microhybrid composite. After 3 months of storage for delayed repair (II), the repair procedures were performed similar to the immediately repaired groups. After 1000 thermal cycles, all specimens were subjected to shear bond strength test.

RESULTS: repair time and surface treatment revealed statistically significant effect on the shear bond strength values of all groups ( $\mathrm{p} \leq 0.05$ ) Highest shear bond strength value was recorded in group I4b (21.97 \pm 1.19$) \mathrm{MPa}$ and the lowest value was recorded in group II1a (4.42 $\pm 0.88 \mathrm{MPa}$ ) CONCLUSIONS: Time of repair, bonding agent and repair material affected repair bond strength of composite.

KEYWORDS: Immediate and delayed repair, adhesion, bonding agent, repair bond strength,

RUNNING TITLE: Repair bond strength of composite resin.

\footnotetext{
1 Master student of Operative Dentistry, Department of Conservative Dentistry, Faculty of Dentistry, Alexandria University, Egypt.

2 Professor of Operative Dentistry, Department of Conservative Dentistry, Faculty of Dentistry, Alexandria University, Egypt.

3 Professor of Dental Biomaterials, Department of Dental Biomaterials, Faculty of Dentistry, Alexandria University, Egypt.
}

* Corresponding author:

E-mail: Emankholief@gmail.com

\section{INTRODUCTION}

One of the most important precepts in modern dentistry is minimally invasive intervention. In case a restoration has been considered as 'failed' and a restorative intervention is needed, there are several options that can be done as repair, sealing and replacement (1). Repair is indicated mainly in the event of localized shortcomings that are clinically unsatisfactory and no longer acceptable; repair is a minimally invasive approach that implies in any case the addition of a restorative material (not only glaze or adhesive), with or without a preparation in the restoration and/or tooth structure (2).

Although repair was not done by all dentists, nowadays repair is more and more considered as state-of-art as it limits the size of the restorative intervention, reduces the risk for complications and limits the costs of intervention. So, dentists are implementing the concept of repair more and more in their clinical practice and modern dental schools are educating their undergraduates repair techniques and indications (3).

Repair, rather than total replacement, is one of the main concepts of minimally invasive dentistry (1).
Many factors affect the bond strength between the prepolymerized resin composite and the newly added composite layer. Among these factors, material compositions, surface conditioning methods in the form of either chemical, mechanical, or combination of both, the use of silane coupling agents and repair time, either immediate or delayed, could all affect the adhesion in repair attempts (4).

One of the important properties of successful restorative dental materials is their repair potential either immediately or after their service in the oral cavity (5). Due to improper handling of the resin composite material, incorrect matrix application or the inappropriate finishing and polishing procedures, the formation of surface voids, under contours, or sub margins at restoration/tooth interface raise the need for immediate repair of resin composite restorations. On the other hand, the presence of discolored margin, marginal ditching, or minimal fracture might also necessitate the repair of aged restorations (6).

During immediate repair, composite is polymerized under the air; an oxygen inhibited layer is always present. This layer 
contains unreacted acrylate groups which improve adhesion between the substrate and the second layer by the formation of covalent bonds. In contrast to the repair of immediately polymerized composites, repair of aged composites represents a challenge due to the depletion of free radicals in the aged composite after the initial polymerization (7).

In repairing composite resin restorations, from a material point of view, adding fresh composite to a cured composite in a repair procedure raises questions about the adhesion and strength of the restoration (8). To achieve chemical adhesion, unreacted double bonds in cured resin-based composites are essential when adding a new layer of material, the surface pretreatment and the intermediate agent were proved to be significant factors of influence on the repair bond strength.

Another factor that could affect the adhesion in repair is surface conditioning. One of the most recent novelties, in adhesive dentistry, was the introduction of universal adhesives. These new products are known as "multi-mode" or "multi-purpose" adhesives because they may be used as selfetch (SE) adhesives, etch-and-rinse (ER) adhesives, or as SE adhesives on dentin and ER adhesives on enamel (a technique commonly referred to as "selective enamel etching". This versatile new adhesion philosophy advocates the use of the simplest option of each strategy, that is, one step self-etch (SE) or two-step etch-and-rinse (ER), using the same single bottle of adhesive solution which is definitely much more challenging to dental substrates of different natures $(9,10)$.

Despite the similarities between adhesives, the composition of universal adhesive differs from the current self-etch systems by the incorporation of monomers that are capable of producing chemical and micromechanical bond adhesion to the dental substrates (11).

Thus, this study was conducted to evaluate the repair bond strength of resin based composite material as a function of different bonding protocols and time. The null hypothesis tested was that repair protocols, repair time and repair composite material did not influence the repair bond strength of resin based composite material.

\section{MATERIALS AND METHODS}

The study was conducted after receiving the approval of the ethical committee at Faculty of Dentistry, Alexandria University, Egypt.

One hundred and sixty discs were prepared from Filtlek z250XT nanohybrid universal composite (3M ESPE, Deutschland, Neuss, Germany) using custom made Teflon mold with central hole of $7 \mathrm{~mm}$ in diameter and $2 \mathrm{~mm}$ in height (12). The composite material was inserted inside the central hole of the mold and covered with mylar strip then adapted using optrasculpt pad to extrude excess material and create a smooth flat polished surface. Then, was photopolymerized using a LED polymerization unit (IvoclarVivadent Inc., Amherst, N.Y., USA) of $800 \mathrm{~mW} / \mathrm{cm} 2$ for $20 \mathrm{sec}$.

The composite discs $(\mathrm{n}=160)$ (thickness: $2 \mathrm{~mm}$; diameter: $7 \mathrm{~mm}$, shade A3.5) were used as pre-polymerized substrate discs.

The discs were randomly divided into 2 main groups of 80 specimens each; Group I represented immediate repair and Group II represented delayed repair (1), then each group was subdivided according to the adhesive received into 4 subgroups; control group, adhese universal group
(IvoclarVivadent Inc., Amherst, N.Y. ,USA) , all bond group (BISCO, Inc.

Schaumburg, USA and scotchbond group (3M ESPE, Deutschland, Neuss, Germany) of 20 specimens each. Each subgroup was subdivided into 2 subgroups according to repair material; tetric evoceram composite (IvoclarVivadent Inc., Amherst, N.Y, USA) and z250 composite (3M ESPE, Deutschland, Neuss, Germany) of 10 specimens each. The descriptions of the adhesives and the composite material included in this study are summarized in Table 1, 2 .

Table 1: List of materials composition

\begin{tabular}{|c|c|c|}
\hline Product & Composition & Manufacturer \\
\hline $\begin{array}{l}\text { Filtek } \\
\text { Z250XT } \\
\text { nanohybrid } \\
\text { Universal } \\
\text { composite }\end{array}$ & $\begin{array}{l}\text { Filler type: Surface-modified } \\
\text { zirconia/silica with a median } \\
\text { particle size of approximately } \\
3 \text { microns or less. Non- } \\
\text { agglomerated/non-aggregated } \\
20 \text { nanometer surface-modified } \\
\text { silica particles } \\
\text { The filler loading is } 82 \% \text { by } \\
\text { weight (68\% by volume) } \\
\text { Resin matrix: Bis-GMA, Bis- } \\
\text { EMA, UDMA, PEGDMA. }\end{array}$ & $\begin{array}{l}\text { 3M ESPE, } \\
\text { Deutschland, } \\
\text { Neuss, } \\
\text { Germany }\end{array}$ \\
\hline $\begin{array}{l}\text { Filtek }^{\mathrm{TM}} \mathrm{Z} 250 \\
\text { microhybrid } \\
\text { Universal } \\
\text { composite }\end{array}$ & $\begin{array}{l}\text { Filler type: zirconia/silica. } \\
\text { Filler loading is } 60 \% \text { by } \\
\text { volume } \\
\text { Resin matrix: A blend of BIS- } \\
\text { GMA, UDMA and Bis-EMA }\end{array}$ & $\begin{array}{l}\text { 3M ESPE, } \\
\text { Deutschland, } \\
\text { Neuss, } \\
\text { Germany }\end{array}$ \\
\hline $\begin{array}{l}\text { Tetricevoceram } \\
\text { nanohybrid } \\
\text { composite }\end{array}$ & $\begin{array}{l}\text { Filler type: contain barium } \\
\text { glass, ytterbium trifluoride, } \\
\text { mixed oxide, and copolymers. } \\
\text { Filler loading 82-83\% by } \\
\text { weight. } \\
\text { Resin matrix: composed of } \\
\text { dimethacrylates } \\
\text { Additives, initiators, } \\
\text { stabilizers, and pigments. }\end{array}$ & $\begin{array}{l}\text { Ivoclar } \\
\text { Vivadent Inc., } \\
\text { Amherst, } \\
\text { N.Y., USA }\end{array}$ \\
\hline $\begin{array}{l}\text { Adhese } \\
\text { Universal } \\
\text { adhesive. }\end{array}$ & $\begin{array}{l}\text { 2-hydroxyethyl methacrylate, } \\
\text { Bis-GMA, ethanol,1,10- } \\
\text { decandiol dimethacrylate, } \\
\text { Methacrylated phosphoric acid } \\
\text { ester (MDP), camphorquinone. }\end{array}$ & $\begin{array}{l}\text { IvoclarVivade } \\
\text { nt Inc., } \\
\text { Amherst, } \\
\text { N.Y., USA }\end{array}$ \\
\hline $\begin{array}{l}\text { All Bond } \\
\text { Universal } \\
\text { adhesive }\end{array}$ & $\begin{array}{l}\text { Bisphenol A } \\
\text { Diglycidylmethacrylate2- } \\
\text { Hydroxyethyl Methacrylate, } \\
\text { Ethanol, MDP. }\end{array}$ & $\begin{array}{l}\text { BISCO, Inc. } \\
\text { Schaumburg, } \\
\text { IL } \\
\text { USA. } \\
\end{array}$ \\
\hline $\begin{array}{l}\text { Scotchbond } \\
\text { Universal } \\
\text { Adhesive }\end{array}$ & $\begin{array}{l}\text { MDP Phosphate Monomer, } \\
\text { Dimethacrylateresins. } \\
\text { HEMA } \\
\text { Vitrebond }{ }^{\mathrm{TM}} \text { Copolymer, } \\
\text { Fillers, Ethanol, Water, } \\
\text { initiators, Silane. }\end{array}$ & $\begin{array}{l}\text { 3M ESPE, } \\
\text { Deutschland, } \\
\text { Neuss, } \\
\text { Germany }\end{array}$ \\
\hline
\end{tabular}

\section{I) Immediate repair procedure (Subgroups I1-I4)}

Composite discs ( $\mathrm{n}=80)$ (thickness: $2 \mathrm{~mm}$; diameter: $7 \mathrm{~mm}$, shade A3.5) were used as pre-polymerized substrate discs. After polymerization, all prepared discs were randomly divided into 4 groups and immediately repaired (shade A1) with cylinder of 3mm in diameter and $5 \mathrm{~mm}$ thickness as follows:

\section{Group 1 (control)}

In this group, 20 discs were left intact with no surface treatment or bonding agent then were divided into 2 subgroups according to repair material

Group 1 (a): no conditioning with Tertric Evoceram nanohybrid composite 
Custom made split Teflon mold (3mm diameter and 5mm thickness) was adjusted over the intact ungrounded surface. Tertric Evoceram composite was packed incrementally inside the mold and gently pressed to extrude excess material and photopolymerized for 20 sec. each increment

\section{Group 1 (b): no conditioning with Filtek ${ }^{\mathrm{TM}}$ Z250 Universal microhybrid composite}

Custom made split Teflon mold was adjusted over the intact ungrounded surface. Filtek ${ }^{\mathrm{TM}}$ Z250 composite was packed incrementally inside the mold and gently pressed to extrude excess material and photopolymerized for 20 sec. each increment.

The remaining discs $(n=60)$ were ground with \#1size diamond bur in one direction, cleaned with water spray, and dried with oil- and moisture-free compressed air. Then, they were divided into 20 discs each according to the bonding agent (was applied according to manufacturer instructions) was used.

Each Subgroup was divided into other 2 subgroups (10 discs each) according to the following repair protocol and composite material.

Group 2 (a) Adhese Universal bond with Tertric Evoceram nanohybrid composite.

Group 2 (b) Adhese Universal bond with Filtek ${ }^{\mathrm{TM}}$ Z250 Universal microhybrid composite.

Group 3 (a) All-Bond Universal with Tertric Evoceram nanohybrid composite.

Group 3 (b) All-Bond Universal with Filtek ${ }^{\mathrm{TM}}$ Z250 Universal microhybrid composite.

Group 4 (a) Scotchbond ${ }^{\mathrm{TM}}$ Universal with Tertric Evoceram nanohybrid composite.

Group 4 (b) Scotchbond ${ }^{\mathrm{TM}}$ Universal with Filtek ${ }^{\mathrm{TM}}$ Z250 Universal microhybrid composite.

II) Delayed repair procedure (subgroups II1 - II4)

Composite discs $(n=80)$ were prepared and stored in the incubator (Fig.12) in artificial saliva at $37^{\circ} \mathrm{C}$ (13) for three months. (1) After three months, the discs were divided into 4 subgroups ( $\mathrm{n}=20$ discs per group) and the repair procedures were performed similar to the immediately repaired groups.

All the repaired specimens were stored in the incubator in distilled water at $37^{\circ} \mathrm{C}$ for 1 week then were subjected to thermo-cycling for 1000 cycles in water bathes with a temperature range of $5-55^{\circ} \mathrm{C}$ with a dwell time of 15 seconds in each bath and 10 seconds transfer time.

The shear bond strength was calculated in MPa according to the following equation:

Shear bond strength $=$ fracture load $(\mathrm{Kg}) /$ surface area of the disc $(\mathrm{cm} 2)$ Where area of the disc $=\pi \mathrm{r} 2$.

Then shear bond strength value in $\mathrm{Kg} / \mathrm{cm} 2$ was converted to MPa by multiplying with 0.09807 .

To identify the failure mode of the specimens, following shear testing de-bonded adhesion surface samples were examined using:

- Stereomicroscope examination: All fractured de-bonded surface samples were examined at 18x magnification to identify the failure mode.

Possible failure modes were classified according to Syprou et al (14) (mixed, adhesive, cohesive). The failure is considered mixed failure if the adhesive interface and the composite material are included (prepolymerized substrate or repair material), adhesive failure, if it occurred at the resin/adhesive interface even if we observed very small amounts of adhesive resin on the composite substrate and cohesive failure, if it occurred in aged composite or in new composite.
- Scanning electron microscopy examination (SEM): Representative specimens of each group were chosen to be further analyzed by SEM to determine the micro morphological topography. Specimens were sputtered by a coating of gold examined at accelerated voltage $15 \mathrm{Kv}$ and viewed at magnification 27x and 1000x.

\section{Statistical analysis of the data}

Data were fed to the computer and analyzed using IBM SPSS software package version 20.0. (Armonk, NY: IBM Corp). The Kolmogorov-Smirnov test was used to verify the normality of distribution Quantitative data were described using range (minimum and maximum), mean, standard deviation and median. Significance of the obtained results was judged at the $5 \%$ level.

The used tests were

\section{1- Student t-test}

For normally distributed quantitative variables, to compare between two studied groups

\section{2- F-test (ANOVA)}

For normally distributed quantitative variables, to compare between more than two groups, and Post Hoc test (Tukey) for pairwise comparisons

\section{3- Two way (ANOVA)}

Was assessed to showing the effect of each factor and the interaction between them

\section{RESULTS}

The highest mean shear bond strength value was recorded in group I4b (immediate repair / scotch bond /z250 composite) $21.97 \pm 1.19 \mathrm{MPa}$, followed by group II4b (delayed repair / scotch bond / z250 composite) $18.71 \pm 1.49 \mathrm{MPa}$, then group I4a (immediate repair/ scotch bond / tetric evoceram composite) $17.66 \pm 2.12 \mathrm{MPa}$ and lowest mean bond strength was recorded in group II1a (delayed repair /control group / tetric evoceram) $4.42 \pm 0.88 \mathrm{MPa}$.

Table 2: Comparison of the mean shear bond strength values in MPa for different bonding agents according to repair time using tetricevoceram as a repair material

\begin{tabular}{|c|c|c|c|c|}
\hline \multirow{2}{*}{ Bonding agents } & \multicolumn{2}{|c|}{ Repair time } & \multirow[b]{2}{*}{$\mathbf{T}$} & \multirow[b]{2}{*}{$\mathbf{p}$} \\
\hline & $\begin{array}{c}\text { Immediate } \\
(\mathbf{I}) \\
(\mathbf{n}=\mathbf{8 0})\end{array}$ & $\begin{array}{c}\text { Delayed } \\
\text { (II) } \\
(\mathbf{n}=\mathbf{8 0})\end{array}$ & & \\
\hline $\begin{array}{l}\text { Control (1) } \\
\text { Min. - Max. } \\
\text { Mean } \pm \text { SD. } \\
\text { Median }\end{array}$ & $\begin{array}{l}5.07-9.10 \\
6.90 \pm 1.27 \\
6.96\end{array}$ & $\begin{array}{l}3.06-5.69 \\
4.42 \pm 0.88 \\
4.40\end{array}$ & $5.092^{*}$ & $<0.001^{*}$ \\
\hline $\begin{array}{l}\text { Adhese bond (2) } \\
\text { Min. - Max. } \\
\text { Mean } \pm \text { SD. } \\
\text { Median } \\
\end{array}$ & $\begin{array}{r}15.11-19.31 \\
17.25 \pm 1.31 \\
17.13\end{array}$ & $\begin{array}{c}9.10-12.31 \\
10.78 \pm 1.16 \\
10.76 \\
\end{array}$ & $11.708^{*}$ & $<0.001^{*}$ \\
\hline $\begin{array}{l}\text { All Bond (3) } \\
\text { Min. - Max. } \\
\text { Mean } \pm \text { SD. } \\
\text { Median } \\
\end{array}$ & $\begin{array}{l}12.91-19.61 \\
15.80 \pm 2.26 \\
15.66 \\
\end{array}$ & $\begin{array}{l}11.12-15.44 \\
13.34 \pm 1.75 \\
13.79\end{array}$ & $2.716^{*}$ & $0.014^{*}$ \\
\hline $\begin{array}{l}\text { Scotch bond (4) } \\
\text { Min. - Max. } \\
\text { Mean } \pm \text { SD. } \\
\text { Median }\end{array}$ & $\begin{array}{c}14.12-21.0 \\
17.66 \pm 2.12 \\
17.36\end{array}$ & $\begin{array}{c}11.07-15.13 \\
13.34 \pm 1.39 \\
13.62 \\
\end{array}$ & $5.392^{*}$ & $<0.001^{*}$ \\
\hline
\end{tabular}

Student t-test was used for statistical analysis to compare between the two main studied groups (immediate and delayed) according to type of bonding agents with the same composite repair material. 
On comparing between different repair times, (immediate vs delayed) using Tetric evoceram composite as repair material (Table 2), higher bond strength values were recorded in immediately repaired groups compared to delayed repair groups using different bonding agents with statistical significant difference between them $(\mathrm{p} \leq 0.05)$.

For immediate repair with Tetric evoceram composite, the highest bond strength value was recorded for scotch bond (I 4) group $17.66 \pm 2.12 \mathrm{MPa}$, followed by adhese bond (I 2) group $17.25 \pm 1.31 \mathrm{MPa}$, then all bond (I 3) group $15.80 \pm 2.26 \mathrm{MPa}$ and the lowest value was recorded in control (I 1) group 6.90 $\pm 1.27 \mathrm{MPa}$.

As for delayed repair, the highest bond strength value was recorded for all bond (II 3) group $13.34 \pm 1.75 \mathrm{MPa}$,followed by scotch bond (II 4) group $13.34 \pm 1.39 \mathrm{MPa}$, then adhese bond (II 2) group $10.78 \pm 1.16 \mathrm{MPa}$ and the lowest value was recorded in control (II1)group 4.42 $\pm 0.88 \mathrm{MPa}$.

When z250 was used as repair material, at different times (immediately and delayed), higher bond strength values were recorded in immediately repaired groups compared to delayed repair groups with statistically significant difference between them $(\mathrm{p} \leq 0.05)$ (Table 3).

For immediate repair with z250 composite, the highest bond strength value was recorded for scotch bond (I 4) group $21.97 \pm 1.19 \mathrm{MPa}$, followed by all bond (I 3) group $17.52 \pm$ $1.35 \mathrm{MPa}$, then adhese bond (I 2) group 15.82 $\pm 1.74 \mathrm{MPa}$ and the lowest value was recorded in control group (I1) $7.46 \pm$ $1.37 \mathrm{MPa}$.

Table 3: Comparison of the mean shear bond strength values in MPa between different bonding agents according to repair time using z250 as a repair material

\begin{tabular}{|c|c|c|c|c|}
\hline \multirow[b]{2}{*}{ Bonding agent } & \multicolumn{2}{|c|}{ Repair time } & \multirow[b]{2}{*}{$\mathbf{T}$} & \multirow[b]{2}{*}{$\mathbf{p}$} \\
\hline & $\begin{array}{c}\text { Immediate } \\
(\mathbf{I}) \\
(\mathbf{n}=\mathbf{8 0}) \\
\end{array}$ & $\begin{array}{c}\text { Delayed } \\
\text { (II) } \\
(\mathbf{n}=\mathbf{8 0})\end{array}$ & & \\
\hline \multicolumn{5}{|l|}{ Control (1) } \\
\hline Min. - Max. & $5.05-9.33$ & $3.01-7.51$ & & \\
\hline Mean \pm SD & $7.46 \pm 1.37$ & $5.12 \pm 1.29$ & & 0.001 \\
\hline Median & 7.67 & 5.13 & & \\
\hline \multicolumn{5}{|l|}{ Adhese bond (2) } \\
\hline Min. - Max. & $12.91-19.15$ & $10.11-14.45$ & & \\
\hline Mean \pm SD. & $15.82 \pm 1.74$ & $12.05 \pm 1.38$ & 5.376 & $<0.001$ \\
\hline Median & 15.66 & 12.13 & & \\
\hline \multicolumn{5}{|l|}{ All Bond (3) } \\
\hline Min. - Max. & $16.12-19.90$ & $9.10-13.21$ & & \\
\hline Mean \pm SD. & $17.52 \pm 1.35$ & $11.53 \pm 1.27$ & 10.194 & $<0.001$ \\
\hline Median & 17.22 & 11.69 & & \\
\hline \multicolumn{5}{|l|}{ Scotch bond (4) } \\
\hline Min. - Max. & $19.96-23.92$ & $15.88-20.2$ & & \\
\hline Mean \pm SD & $21.97 \pm 1.19$ & $18.71 \pm 1.49$ & 5.415 & $<0.001$ \\
\hline Median & 21.98 & 19.08 & & \\
\hline
\end{tabular}

t: Student t-test

$\mathrm{p}$ : p value for associated between different categories

*: Statistically significant at $\mathrm{p} \leq 0.05$

As for delayed repair, the highest bond strength value was recorded for scotch bond group(II 4) $18.71 \pm 1.49 \mathrm{MPa}$, followed by adhese bond group (II2) $12.05 \pm 1.38 \mathrm{MPa}$, then all bond group (II 3) $11.53 \pm 1.27 \mathrm{MPa}$ and the lowest value was recorded in control group (II 1) $5.12 \pm 1.29 \mathrm{MPa}$.

Comparison between the different studied groups according to stereomicroscope results demonstrated:
In immediately repaired group (I), 40 (50\%) specimens showed adhesive failure at the repair interface (figure 1), 26 specimens (32.5\%) showed mixed failure (figure 2), 14 specimens (17.5\%) showed cohesive failure (figure 3)

In delayed repair group (II), 40 (50\%) specimens showed adhesive failure at the repair interface, 39 specimens (48.8\%) showed mixed failure, 1 specimen (1.3\%) showed cohesive failure.

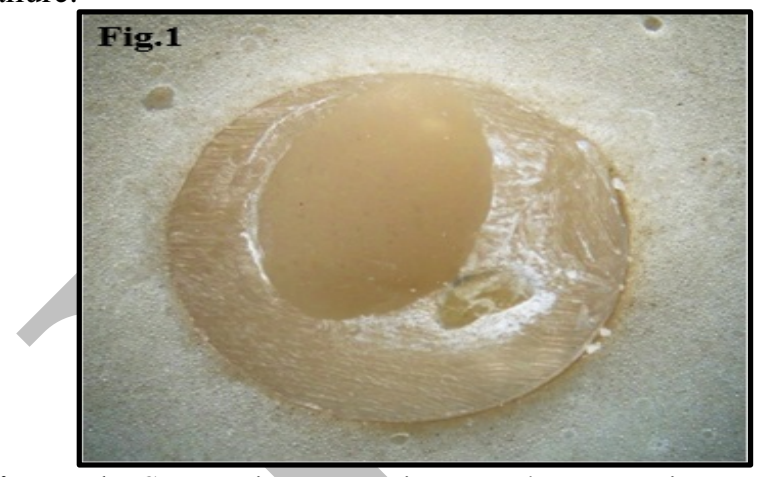

Figure 1: Stereomicroscope images demonstrating mode of failure in repaired groups showing Adhesive pattern of failure.

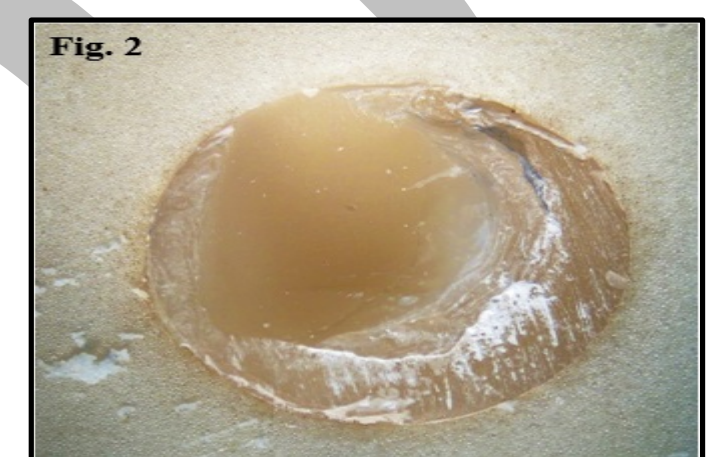

Figure 2: Stereomicroscope images demonstrating mode of failure in repaired groups showing Mixed pattern of failure.

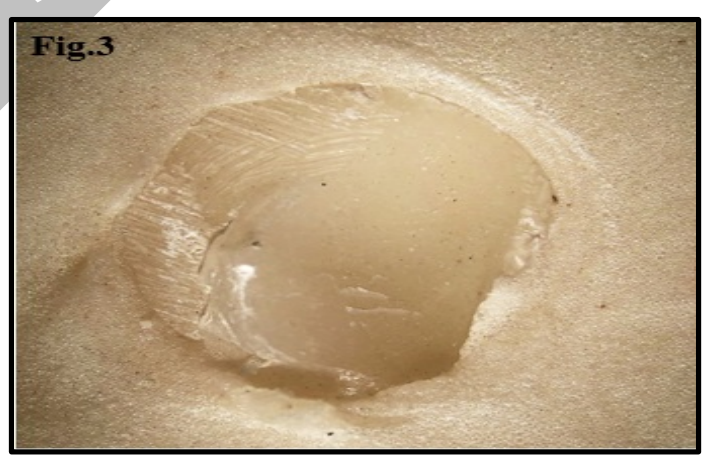

Figure 3: Stereomicroscope images demonstrating mode of failure in repaired groups showing cohesive pattern of failure.

\section{DISCUSSION}

Dental resin-based composites (RBCs), which are used in restoration of anterior and posterior teeth, still have limited lifetime. Dynamic changes in $\mathrm{pH}$ and temperature in the oral cavity due to diet, saliva, and aging lead to degradation in the resin composite during clinical service. These changes may lead to various defects including microleakage, discoloration, wear, chipping, ditching or fracture which results in the replacement of the restoration (15).

The present study was conducted to evaluate bond strength for immediate and delayed repair of nanohybrid 
composite with microhybrid and nanohybrid resins using different bonding agents.

Bond strength of repaired restoration depends on numerous factors such as substrate surface condition, time of repair, storage media before and after repair, presence and composition of intermediate agent, chemical microstructure of the substrate, and repair material. The key factor for the success of resin composite repair is achieving high bond strength between the previously polymerized composite and the freshly added one (16).

In the present study, the specimens were equally divided into 2 groups, half of them received rebonding procedures 24 hours immediately after specimen preparation. The other half were stored for 3 months in artificial saliva in thermal incubator at $37^{\circ} \mathrm{C}$ to mimic clinical service in oral environment

According to Brosh et al (17) the bonding of old and new composite resin, occurs by three distinct means, that is, chemical bonding with the organic matrix, chemical bonding with exposed filler particles and through micromechanical retention to the treated surface. So, in this study specimens received surface treatment with a diamond bur that allowed penetration of the repair composite into the surface of the composite disc and increased surface area for bonding.

The adhesive system used in this study was universal adhesives (Adhese universal, all bond universal and Scotchbond universal) in self-etch mode as it was reported that high bond strength when aged restorations were repaired with a self-etching system. Teixeira et al (18) also stated that the technique used to apply the selfetching system influence the rebonding procedure positively and the light brushing motion may allow an easier penetration of the solvent and monomer into the surface to be repaired. The repair protocol of composite restorations, using universal adhesives were used in this study similar to Fornazari et al (19) and Elisson et al (20) who used universal adhesive in repair of composite. Also, Tantbirojn et al (21) investigated a universal adhesive as a bonding agent for the repair of a nanofilled composite.

In this study, the prepolymerized substrates to be repaired were made from nanohybrid composite (z250XT) as they offer the advantages of durability, low polymerization shrinkage, high polishability, easy handling and superior esthetic properties due to their nano-sized filler particles and higher filler content (20). Two different repair materials were used as it may not always be possible to clinically determine the composition or brand of the old composite, some researchers used resin composite of the same type, whereas other studies used dissimilar resin composites. So, these prepolymerized substrates were repaired with another nanohybrid (tetric evoceram) and with microhybrid composite (Z250).

Similar to De Jesus Tavarez (13) who assessed repair bond strength with the influence of surface treatment and different types of composite resin. Also, Baur and Ilie (22) reported that it was not the same to repair resin composites with the same material or in combination with other materials

The results of the present study support the rejection of the null hypothesizes that repair time, bonding agent and repair material did not affect the bond strength of repaired composite.

From the results of this study, it was found that the bond strength was greater in the immediately repaired groups than delayed repair with statistically significant difference between them. These findings in the present study had suggested the availability of free radicals in composite resins responsible for adhesion between different composite layers. These free radicals decrease following aging. The greatest activity of residual free radicals of substrate occurs within 24 hours after composite polymerization (13).

This was in agreement with Deeb et al (23) and El Askary et al (24) who found that immediately repaired composite has bond strength greater than the delayed one.

In this study, there was a control group without any surface treatment to assess the effect of oxygen inhibited layer on repair bond strength of composite similar to Kashi et al (25) and Eliasson et al (26) who added control group in their studies. The lowest shear bond strength values were recorded in control groups in delayed repaired group (4.42 $\pm 0.88 \mathrm{MPa}$, $5.12 \pm 1.29 \mathrm{MPa})$. This is may be due to the limited number of reactive methacrylate groups left in the preexisting composite resin after polymerization and water sorption.

Repaired groups with surface treatment using a diamond bur and bonding agents (mean for them 17.25, 15.8,17.66 $\mathrm{MPa}$ ) exhibit higher shear bond strength values than control groups (mean for them 6.9, 7.4, 4.42,5.12 MPa) with statistically significant difference between them. This result because of surface irregularities created with diamond bur that resulted in creating a retentive surface that enables mechanical interlocking of the new material, removes the superficial layer which is chemically altered by exposure to the oral environment and increase surface energy of old composite.

Our results agreed with Bonstein et al (27) and El Namsi et al (28) who found that surface roughening of aged composites with a diamond bur exhibited higher bond strength.

In addition to Oskoee et al (29) concluded that surface roughness might enhance the ability of fresh composite to interlock mechanically into the substrate, because increased surface area is available for micro-mechanical bonding. Tabatabaie et al (30) mentioned that following the use of bur, macroretentive and microretentive areas are created, which increase bond strength.

In this study, three different universal adhesives were used (Adhese universal, all bond universal and Scotchbond universal). Highest bond strength $(21.97 \pm 1.19 \mathrm{MPa})$ was recorded in scotchbond universal adhesive group with statistically significant difference $(p \leq 0.05)$ between the other bonding agents used at different repair times.

As adhesive Scotchbond Universal adhesive contains, in addition to conventional methacrylate monomers, 10-MDP, a functional monomer known for its ability to bond chemically to calcium and make the adhesive interface more resistant to biodegradation. Furthermore, it contains prehydrolyzed silane, claimed by the manufacturer to be stable up to at least one year in storage (31).

Our results showed that the effectiveness of the universal adhesive was independent of the type of silane but that the repair bond strength increased when this type of adhesive was used with surface treatment, probably because this resulted in a greater proportion of exposed fillers at the surface of the composite, increasing the surface area for bonding (32).

Our results were similar to Fornazari et al (19) who concluded that using of silane containing adhesives (scotchbond universal adhesive) alone was effective in the repair bond strength. Also, Maneenut et al (33) reported that silane-based adhesives had stronger bond strength than that of adhesives without silane. 
However, it was found that shear bond strength values in this study, between prepolymerized substrates and repaired with nanohybrid composite (tetric evoceram) is less than repaired with microhybrid (z250) in both repair times. This may be due to the presence of zirconium particles that prevented proper surface preparation of these composites, therefore most of the samples have weak bond strength (34).

On the contrary, the highest bond strength was recorded in scotchbond with z250 microhybrid composite $(21.97 \pm 1.19$ $\mathrm{MPa}$ ) because the water absorbed had less effect on the repair bond strength of composite with silane adhesive.

As the repair bond strength depends on the material in which filler content and size are the most important factors when composite absorbs water. The contribution of resin matrix to repair bonding performance is influenced by water sorption/solubility. The homogeneity of cured and freshly added composite may be useful for copolymerization performance between their matrix monomers (35).

These results were similar to Sadaghiani et al (36) who found that the nanohybrid composite showed a weaker repairability as compared to the micro hybrid composite. Also, Nagano et al (37) stated that microhybrid composite was a more suitable material for repair than nanohybrid composite due to adhesion to exposed large silica filler.

In contrast, Ozcan et al (34) stated that the composite type did not affect the repair bond strength significantly.

In the present study, on analyzing the failure modes according to the previously mentioned classification, most of the adhesive failure were recorded in control groups (I1 and II1) which indicated the weak interfacial bond could be attributed to the absence of surface treatment and bonding agent during composite repair. Thus, it is important to have treatment protocol in repairing composite restoration to obtain durable bond (3).

In general, failure modes indicate that those groups with high bond strengths exhibit cohesive failure inside the composite. However, low bond strength groups tend to exhibit adhesive failure rather than cohesive failure. Fractures within the composite resin (cohesive failure) seem to be more appropriate for bearing occlusal loads (21). All the cohesive fractures occurred in the old composite. More cohesive fractures were found in the stronger repair groups. Most cohesive failure was in groups I4b and II4b, which also had the highest mean repair strength.

This result agreed with Kashi et al (25) who found most of the adhesive failure occurred in control group. Our results also agreed with Fornazari et al (19) who found that polished specimens exhibit over $80 \%$ adhesive failures.

When the SEM images were analyzed, adhesive failures were more likely to occur between the prepolymerized substrate and repair material and most commonly occurred in control group.

According to the results, the lowest repair bond strength was recorded in the control group, which was expected due to smooth surface visible in scanning electron micrograph of the sample in this group and indicates the importance of surface roughening in improving the repair bond strength of composite resins.

Similar to Ahmadizenouz et al (38) where SEM revealed the smooth surface of control group exhibit lower adhesive strength than roughed surface.

\section{CONCLUSIONS}

Within the limitations of this study, the following conclusions can be addressed:

1. Treating the surface of the aged composite is necessary when fresh composite is added. With no treatment, nearly no bond exists between the two materials.

2. All bonding agents studied here showed acceptable results.

3. Use of bonding agent containing silane after mechanical grinding produced the best results.

4. Long-term storage considerably decreased the repair SBS, regardless of the treatment used.

\section{CONFLICT OF INTREST}

The authors declare that they have no conflicts of interest.

\section{REFERENCES}

1. Ástvaldsdóttir Á, Dagerhamn J, van Dijken JW, NaimiAkbar A, Sandborgh-Englund G, Tranæus S. Longevity of posterior resin composite restorations in adults - A systematic review. J Dent. 2015; 43:934-54.

2. Hickel R, Brüshaver K, Ilie N. Repair of restorations-criteria for decision making and clinical recommendations. Dent Mater. 2013; 29:28-50.

3. Wendler M, Belli R, Panzer R, Skibbe D, Petschelt A, Lohbauer U. Repair Bond Strength of Aged Resin Composite after Different Surface, and Bonding Treatments. Materials. 2016; 9:547.

4. Hickel R, Peschke A, Tyas M, Mjör I, Bayne S, Peters $\mathrm{M}$, et al. FDI World Dental Federation - clinical criteria for the evaluation of direct and indirect restorations. Update and clinical examples. J Adhes Dent. 2010; 12:259-72.

5. Rinastiti M, Ozcan M, Siswomihardjo W, Busscher HJ. Immediate repair bond strengths of microhybrid, nanohybrid and nanofilled composites after different surface treatments. J Dent. 2010; 38:29-38.

6. Ozcan M, Pekkan G. Effect of different adhesion strategies on bond strength of resin composite to composite-dentin complex. Oper Dent. 2013; 38:63-72.

7. Atalay C, Yazici AR, Ozgunaltay G. Bond strengths of bulk-fill resin composite repairs: effect of different surface treatment protocols in vitro. J Adhes Sci Technol. 2018; 32:921-30.

8. Özcan M, Koc-Dundar B. Composite-composite adhesion in dentistry: a systematic review and metaanalysis. J Adhes Sci Technol. 2014; 28:2209-29.

9. Van Meerbeek B, Yoshihara K, Yoshida Y, Mine A, De Munck J, Van Landuyt KL. State of the art of self-etch adhesives. Dent Mater. 2011; 27:17-28.

10. Fukegawa D, Hayakawa S, Yoshida Y, Suzuki K, Osaka A, Van Meerbeek B. Chemical interaction of phosphoric acid ester with hydroxyapatite. J Dent Res. 2006; 85:941-4.

11. Van Landuyt KL, Yoshida Y, Hirata I, et al. Influence of the chemical structure of functional monomers on their adhesive performance. J Dent Res. 2008; 87:75761.

12. El-Askary FS, Salah M, Anwar MN, Özcan M. Immediate and delayed repair bond strength of a new ormocer resin restorative material as a function of mechanical and chemical surface conditioning methods. J Adhes Sci Technol. 2017; 31:310-26. 
13. de Jesus Tavarez RR, Almeida Júnior LJDS, Guará TCG, Ribeiro IS, Maia Filho EM, Firoozmand LM. Shear bond strength of different surface treatments in bulk fill, microhybrid, and nanoparticle repair resins. Clin Cosmet Investig Dent. 2017; 9:61-6.

14. Spyrou M, Koliniotou-Koumpia E, Kouros P, Koulaouzidou E, Dionysopoulos P. The reparability of contemporary composite resins. Eur J Dent. 2014; 8:353-9.

15. Koç-Vural U, Kerimova L, Baltacioglu İH, Kiremitçi A. Bond strength of dental nanocomposites repaired with a bulkfill composite. J Clin Exp Dent. 2017; 9: e437-42.

16. Abo El Naga A, Zahran R. The Microshear Bond Strength of Repaired Resin Composite after Different Surface and Bonding Treatments. J Am Sci. 2017; 13:79-86.

17. Brosh T, Pilo R, Bichacho N, Blutstein R. Effect of combinations of surface treatments and bonding agents on the bond strength of repaired composites. J Prosthet Dent. 1997; 77:122-6.

18. Teixeira EC, Bayne SC, Thompson JY, Ritter AV, Swift EJ. Shear bond strength of self-etching bonding systems in combination with various composites used for repairing aged composites. J Adhes Dent. 2005; 7:159-64.

19. Fornazari IA, Wille I, Meda EM, Brum RT, Souza EM. Effect of Surface Treatment, Silane, and Universal Adhesive on Microshear Bond Strength of Nanofilled Composite Repairs. Oper Dent. 2017; 42:367-74.

20. Eliasson ST, Tibballs J, Dahl JE. Effect of different surface treatments and adhesives on repair bond strength of resin composites after one and 12 months of storage using an improved microtensile test method. Oper Dent. 2014; 39: E206-16.

21. Tantbirojn D, Fernando C, Versluis A. Failure Strengths of Composite Additions and Repairs. Oper Dent. 2015; 40:364-71.

22. Baur V, Ilie N. Repair of dental resin-based composites. Clin Oral Investig. 2013; 17:601-8.

23. El-Deeb HA, Ghalab RM, Elsayed Akah MM, Mobarak EH. Repair bond strength of dual-cured resin composite core buildup materials. J Adv Res. 2016; 7:263-9.

24. El-Askary FS, El-Banna AH, van Noort R. Immediate vs delayed repair bond strength of a nanohybrid resin composite. J Adhes Dent. 2012; 14:265-74.

25. Kashi TJ, Erfan M, Rakhshan V, Aghabaigi N, Tabatabaei FS. An in vitro assessment of the effects of three surface treatments on repair bond strength of aged composites. Oper Dent. 2011; 36:608-17.

26. Eliasson ST, Dahl JE. Effect of curing and silanizing on composite repair bond strength using an improved micro-tensile test method. Acta Biomater Odontol Scand. 2017; 3:21-9.

27. Bonstein T, Garlapo D, Donarummo J. Bush PJ. Evaluation of varied repair protocols applied to aged composite resin. J Adhes Dent. 2005; 7:41-9.
28. El namsi NM. Effect of some repair protocols on the repair bond strength to strength to a nanocomposite. Egypt Dent J. 2013; 61:1-9.

29. Oskoee PA, Kimyai S, Talatahari E, Rikhtegaran S, Pournaghi-Azar F, Oskoee JS. Effect of mechanical surface treatment on the repair bond strength of the silorane-based composite resin. J Dent Res Dent Clin Dent Prospects. 2014; 8:61-6.

30. Tabatabaei MH, Alizade Y, Taalim S. Effect of various surface treatment on repair strength of composite resin. J Dent (Tehran). 2004; 1:5-11.

31. Alex G. Universal adhesives: the next evolution in adhesive dentistry? Compend Contin Educ Dent. 2015;36:15-26.

32. Ayar MK, Guven ME, Burduroglu HD, Erdemir F. Repair of aged bulk-fill composite with posterior composite: Effect of different surface treatments. J Esthet Restor Dent. 2019; 31:246-52.

33. Maneenut C, Sakoolnamarka R, Tyas MJ. The repair potential of resin composite materials. Dent Mater. 2011;27: e20-7.

34. Özcan M, Corazza PH, Marocho SM, Barbosa SH, Bottino MA. Repair bond strength of microhybrid, nanohybrid and nanofilled resin composites: effect of substrate resin type, surface conditioning and ageing. Clin Oral Investig. 2013; 17:1751-8.

35. Bociong K, Szczesio A, Sokolowski K, Domarecka M, Sokolowski J, Krasowski et al. The influence of water sorption of dental lightcured composites on shrinkage stress. Materials (Basel). 2017; 10:1142.

36. Sadaghiani M, Rahbar M, Saati K, Kokabi H, Amini S. Comparison of the Micro-Tensile Bond Strength of Composite Resin Restoration in Micro-and Nano-hybrid Composite Resins using Different Interfacial Materials. JRMDS. 2018; 6:436-44.

37. Nagano D, Nakajima $M$, Takahashi $M$, Ikeda $M$, Hosaka K, Sato K, et al. Effect of Water Aging of Adherend Composite on Repair Bond Strength of Nanofilled Composites. J Adhes Dent. 2018; 20:425-33. Ahmadizenouz G, Esmaeili B, Taghvaei A, Jamali Z, Jafari $\mathrm{T}$, Amiri Daneshvar F, et al. Effect of different surface treatments on the shear bond strength of nanofilled composite repairs. J Dent Res Dent Clin Dent Prospects. 2016; 10:9-16. 